\title{
Requirement of Postoperative Ventilation and analgesics during Off-Pump Coronary Artery Bypass (OPCAB) surgery - A Comparison between Combined High Thoracic Epidural Anaesthesia (HTEA) with GA and GA Alone
}

\author{
SI Azad, AK Beg
}

\begin{abstract}
:
Beckground: This is often difficult to achieve optimal pain relief after coronary artery bypass surgery and also great challenge to choice appropriate analgesics with minimize the duration of mechanical ventilation. In the postoperative period inadequate analgesia may increase morbidity by causing adverse haemodynamic, metabolic, immunologic and haemostatic attentions and prolong mechanical ventilation with more ICU stay. High Thoracic Epidural Anaesthesia (HTEA) as an adjunct to general anaesthesia has been shown to be potentially beneficial in postoperative pain relief and the requirement of mechanical ventilationin patients with off-pump coronary artery bypass surgery (OPCAB). HTEA provides good protection from stress response, ensures hemodynamic stability, improves distribution of coronary blood flow with reducing demand of oxygen, less requirement of postoperative analgesia, mechanical ventilation and ICU stay.
\end{abstract}

Objective: This study has been undertaken with a view to compare requirement of postoperative mechanical ventilation and analgesics in OPCAB surgery between HTEA with GA and GA alone.

Methods: This prospective, randomized case control comparative study was carried out in sixty patients without having left main coronary artery disease, left ventricular ejection fraction $<30 \%$ or contraindication of regional anaesthesia scheduled for OPCAB. They were divided into two groups, thirty in each group. Group $A$ received $G A$ alone and group $B$ received high thoracic epidural anaesthesia with GA. Requirement of postoperative analgesics, pain score, consciousness score, sedation score, satisfection level and duration of ventilation with length of stay in intensive care unit were recorded in the post-operative period.

Results: Rescue analgesics received and found $16(53.3 \%)$ and $6(20.0 \%)$ needed analgesia in group $A$ and group $B$ respectively and the difference was statistically significant $(p<0.05)$. Regarding the pain score (VAS) during maintenance with ventilator with awareness at first fourth hour significant $(p<0.05)$ change between two groups. After extubation at rest in different time interval and found significant $(p<0.05)$ change between two groups in all follow-up times. Post-operative pain score (VAS) after extubation at movement in different time interval and found significant $(p<0.05)$ change between two groups. Post-operative pain score (VAS) after extubation at during coughing in different time interval and found significant $(p<0.05)$ change between two groups. Post-operative sedation score at first six hour (hourly) and found significant $(p<0.05)$ change between two groups except 1st hour, which was not significant $(p>0.05)$. The mean extubation hours were $7.4 \pm 1.09$ hours in group $A$ and $5.3 \pm 0.81$ hours in group $B$. The mean ICU stay was $72.9 \pm 9.2$ hours in group $A$ and $57.1 \pm 12.0$ hours in group $B$ and the difference was statistically significant $(p<0.05)$ in unpaired t-test. No postoperative complication was observed in both groups.

Conclusion: HTEA with GA appeared to be most reliable postoperative pain relief, shorter mechanical ventilation, ICU stay in OPCAB surgery

Key word: pain, ventilation, analgesics, OPCAB, postoperative, epidural, HTEA, General anaesthesia.

1. Associate Professor, Department of Anaesthesiology, National Institute of Cardiovascular Diseases (NICVD), Dhaka, Bangladesh.

2. Professor, Department of Anaesthesiology, National Institute of Cardiovascular Diseases (NICVD), Dhaka, Bangladesh.

Address of Correspondence: Dr.Saiful Islam Azad, Department of Anaesthesiology, National Institute of Cardiovascular Diseases (NICVD), Dhaka. Bangladesh. Email: saifulazad@yahoo.com

DOI: https://doi.org/10.3329/bhj.v36i2.56032

Copyright $\odot 2017$ Bangladesh Cardiac Society. Published by Bangladesh Cardiac Society. This is an Open Access articles published under the Creative Commons Attribution-NonCommercial 4.0 International License (CC BY-NC). This license permits use, distribution and reproduction in any medium, provided the original work is properly cited and is not used for commercial purposes. 


\section{Introduction:}

Pain control with thoracic epidural is probably the most easily documented benefit. All studies examining the use of thoracic epidurals for cardiac surgery have documented superior pain relief when compared to all other modalities, including intrathecal opiate analgesia.

It is important to use TEA to its maximum capacity to benefit from its full potential: outstanding analgesia, excellent protection against stress hormone surge after surgery, reduction of postoperative ventilation period, fast recovery and better pulmonary recovery outcome. It seems imperative to begin its use before surgery starts, continue its infusion at a constant rate during surgery, and carry on for at least 2 days if possible. One study has shown that the maximum pain after surgery occurs within the first 48 hours, after which pain subsides significantly. In addition, use of TEA for longer than 3 days carries the risk of losing the control over its use and increase the likelihood of human error due to miscommunication. The safest duration of TEA in cardiac surgery is a maximum of 3 days; exceptionally longer use should be justified on a patient-by-patient basis .In the postoperative period inadequate analgesia may increase morbidity by causing adverse haemodynamic, metabolic, immunologic and haemostatic attentions (Chancy, 2006; Weissman, 1990; Kehlet, 1989; Roizen, 1988). This is often difficult to achieve optimal pain relief.

Aim:

- To assess postoperative pain score, consciousness score and sedation score between HTEA with GA and GA alone.

- To observe duration of ventilation and length of stay in intensive care unit between HTEA with GA and GA alone.

- To observe the requirement of post-operative rescue analgesia.

\section{Methodology:}

After selection of patients according to the inclusion and exclusion criteria, and after obtaining informed consent, a total of 60 adult patients with coronary artery diseases were prospectively enrolled in this study. All patients were undergone elective $\mathrm{CABG}$ on the beating heart with complete median sternotomy either using General
Anaesthesia alone (group A) or combined High Thoracic Epidural Anaesthesia with General Anaesthesia (group B). All patients were premedicated Tab. Midazolam 7.5 $\mathrm{mg}$ received at bed time day before operation. On the arrival in the operation theater, patients were pre oxygenated and after stablist ECG monitor with all aseptic precaution intravenous cannulation, radial arterial cannulation and central venous catheterization was established in both groups. In the group B (study group), with all aseptic precaution a side holed multiport epidural catheter was inserted through $18 \mathrm{G}$ Touhy needle at the level of T1-2 or T2-3 interspaces in the morning on the day of surgery under local anaesthesia using midline approach at lateral decubitus position with the loss of resistance or hanging drop technique. The catheter was directed cephalic and advance 3-4 cm into the epidural space. Continuous epidural infusion with $0.25 \%$ bupivacaine was maintained after operation @ 4-5 ml/ hr up to 48 hours. Sensory block was determined bilaterally using loss of warm- cold sensation as well pinprick discrimination.

In both groups general anaesthesia was induced with fentanyl $10 \mu \mathrm{g} / \mathrm{kg}$ IV and with propofol $1 \mathrm{mg} / \mathrm{kg}$ IV. Tracheal intubation was facilitated by pancuronium bromide 0.1 $\mathrm{mg} / \mathrm{kg}$. Anaesthesia was maintained with propofol infusion @ 3-6 mg/kg/hr (50-100 $\mathrm{gg} / \mathrm{kg} / \mathrm{min})$ and fentanyl infusion @ 1-2 $\mu \mathrm{g} / \mathrm{kg} / \mathrm{hr}$, neuromuscular booking agent pancuronium bromide $1 / 3^{\text {rd }}$ dose of induction dose was given at one hour interval through iv route. The lungs were ventilated mechanically at normocapnia in an air and Oxygen mixture.

The parameters including heart rate $(\mathrm{HR})$, arterial blood pressure (ABP), ECG, $\mathrm{SPO}_{2}, \mathrm{CVP}, \mathrm{ABG}$ analysis, Urine output were monitored during operation. Ephedrine 5$10 \mathrm{mg}$ iv bolus or repeated was given if hypotension associated with epidural anaesthesia, dopamine 1-20 $\mu \mathrm{g} / \mathrm{kg} / \mathrm{min}$ was the first choice to maintain MAP above 70 $\mathrm{mmHg}$ if not corrected then adrenaline $0.05-0.2 \mu \mathrm{g} / \mathrm{kg} /$ min, dobutamine $2-20 \mu \mathrm{g} / \mathrm{kg} / \mathrm{min}$ was added accordingly.

On the arrival at ICU from Operation Theater the patient, ventilation was maintained by mechanical ventilator. Mechanical ventilation was started in assist control mode with a respiratory rate $10-12$ breath / min, Tidal volume $10 \mathrm{ml} / \mathrm{kg}, \mathrm{FiO}_{2}: 0.7$ and was adjusted to maintain $\mathrm{O}_{2}$ saturation by pulse oxymetry $>95 \%$ and PEEP was set at 
$5 \mathrm{~cm} \mathrm{H}_{2} \mathrm{O}$. Tidal volume was adjusted to maintain partial pressure of arterial $\mathrm{CO}_{2}$ between 35 and $40 \mathrm{~mm} \mathrm{Hg}$. When patient is haemodynamically stable and arousal, ventilation mode was changed to SIMV then Spontaneous ventilation mode. When there were accepted criteria for tracheal extubation then the patient was extubated and postoperative mechanical ventilation hour was recorded. Postoperative analgesia was performed by the epidural infusion $0.25 \%$ bupivacaine 3-4 $\mathrm{ml} /$ hour in patients group $\mathrm{B}$ and both groups of the patients were received injection ketorolac $30 \mathrm{mg}$ iv 8 hourly.

Pain exceeding a visual analog score (VAS 0-100) of 50 or whenever were requested by the patients or deemed necessary by the nurse in case the patients are not fully awake and able to respond sufficiently, the hourly epidural rate was increased by $1 \mathrm{ml}$ and intravenous Ketorolac $30 \mathrm{mg}$ was administered simultaneously for instant pain relief. Morphine 1-2 mg IV as needed was used if ketorolac were insufficient. These rescue analgesics need were recorded. The epidural catheter was removed after 48 hours of post-operative period with normal coagulation profile.After extubation the level of consciousness (LOC) was hourly assessed for 6 hours using 5-point LOC scale. A higher score on the LOC were indicated a poorer LOC. After awareness postoperative pain scores were assessed and recorded of all patients at rest, exercise (e.g. Movement, coughing and so on) using a $100-\mathrm{mm}$ visual analog scale, with ends marked as 0 (no pain) and $100 \mathrm{~mm}$ (worst imaginable pain) every four hour interval for 48 hours postoperatively. Sedation score was assessed and recorded by using a 3 - point scale (1, completely awake and open eyes; 2 , asleep but responds to verbal commands and/or touch; 3 , does not respond) every hourly for first six hour of postoperative period. On the $3^{\text {rd }}$ post-operative day all patients were questioned as to satisfaction and whether they would choose the anaesthetic technique again and ask to other patients to receive this anaesthetic technique. After accepted criteria for discharge from the intensive care unite (ICU) patient was shifted to the post-operative care unit and the duration of ICU stay was recorded. Following post-operative complications were recorded in this study.

Pneumothorax: Evidenced on chest $\mathrm{x}$-ray for consecutive post-operative 3 days.Prolong mechanical ventilation: Tracheal intubation for more than 24 hours, tracheal reintubation after initial extubation. Neurologic complication: Assessed with sensory, motor or reflex abnormalities any time after surgery; global abnormalities within two days operation.Acute infection: Patients were defined as confused when, after extubation they were unable either to cooperate or communicate with the nurses and were disoriented in time and place for 8 hours or more.Epidural haematoma: Suspected if patients had radicular pain on the back, sensory, motor deficits, and urinary retention diagnosed was confirm with immediate MRI.

\section{Results:}

The mean $( \pm S D)$ age of the study patients were $49.9 \pm 7.1$ years in group $A$ and $49.3 \pm 7.2$ years in group $B$. The mean $( \pm S D)$ body surface area (BSA) of the study patients were $1.6 \pm 0.11 \mathrm{~m}^{2}$ in group $A$ and $1.7 \pm 0.15 \mathrm{~m}^{2}$ in group $B$. No significant $(p>0.05)$ mean age and body surface area (BSA) differences were found between two groups in unpaired t-test .

During postoperative ventilation with awareness at first fourth hour and after extubation from ventilator at rest and during movement in different time interval significant $(p<0.05)$ change found regarding pain score (VAS) between two groups.

\section{Table-I}

Post-operative pain score (VAS) during maintenance with ventilator with awareness at different times of the study patients $(n=60)$

\begin{tabular}{lccc}
\hline & $\begin{array}{c}\text { Group A } \\
(\mathrm{n}=30) \\
\text { Mean } \pm S D\end{array}$ & $\begin{array}{c}\text { Group B } \\
(\mathrm{n}=30)\end{array}$ & pvalue \\
Mean $\pm S D$ & \\
\hline $1^{\text {st }}$ fourth hour & $53.4 \pm 9.4$ & $26.0 \pm 8.7$ & 0.001 \\
\hline
\end{tabular}

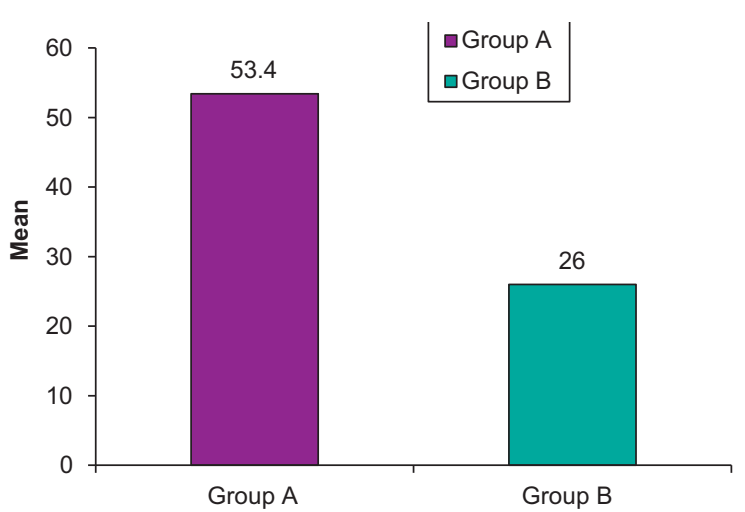

Fig.-1: Bar diagram showing post-operative pain score (VAS) during maintenance with ventilator with awareness at different times of the study patients. 
Table-II

Post-operative pain score (VAS) after extubation at rest in different time interval of the study patients $(n=60)$

\begin{tabular}{lccc}
\hline $\begin{array}{l}\text { Four hours time } \\
\text { interval }\end{array}$ & $\begin{array}{c}\text { Group A } \\
(\mathrm{n}=30) \\
\text { Mean } \pm \text { SD }\end{array}$ & $\begin{array}{c}\text { Group B } \\
(\mathrm{n}=30) \\
\text { Mean } \pm S D\end{array}$ & pvalue \\
\hline $8^{\text {th }}$ hour & $47.5 \pm 9.6$ & $23.3 \pm 5.0$ & 0.001 \\
$12^{\text {th }}$ hour & $47.5 \pm 8.8$ & $23.3 \pm 5.8$ & 0.001 \\
$16^{\text {th }}$ hour & $45.3 \pm 5.1$ & $22.3 \pm 5.3$ & 0.001 \\
$20^{\text {th }}$ hour & $42.1 \pm 6.1$ & $21.9 \pm 5.3$ & 0.001 \\
$24^{\text {th }}$ hour & $42.5 \pm 6.2$ & $21.5 \pm 4.3$ & 0.001 \\
$28^{\text {th }}$ hour & $41.7 \pm 5.9$ & $21.5 \pm 4.3$ & 0.001 \\
$32^{\text {th }}$ hour & $40.5 \pm 4.6$ & $21.5 \pm 4.3$ & 0.001 \\
$36^{\text {th }}$ hour & $40.7 \pm 4.7$ & $21.5 \pm 4.3$ & 0.001 \\
$40^{\text {th }}$ hour & $40.2 \pm 5.7$ & $21.2 \pm 4.2$ & 0.001 \\
$44^{\text {th }}$ hour & $39.5 \pm 5.1$ & $21.5 \pm 5.2$ & 0.001 \\
$48^{\text {th }}$ hour & $37.8 \pm 4.6$ & $21.3 \pm 4.3$ & 0.001 \\
\hline
\end{tabular}

Table-III

Post-operative pain score (VAS) after extubation at movement in different time interval of the study patients $(n=60)$

\begin{tabular}{lccc}
\hline $\begin{array}{l}\text { Four hours time } \\
\text { interval }\end{array}$ & $\begin{array}{c}\text { Group A } \\
(\mathrm{n}=30) \\
\text { Mean } \pm \text { SD }\end{array}$ & $\begin{array}{c}\text { Group B } \\
(\mathrm{n}=30) \\
\text { Mean } \pm S D\end{array}$ & pvalue \\
\hline $8^{\text {th }}$ hour & $\begin{array}{c}51.2 \pm 7.5 \\
25.0 \pm 6.1\end{array}$ & 0.001 \\
$12^{\text {th }}$ hour & $52.5 \pm 8.6$ & $24.8 \pm 6.9$ & 0.001 \\
$16^{\text {th }}$ hour & $48.5 \pm 4.8$ & $23.8 \pm 5.8$ & 0.001 \\
$20^{\text {th }}$ hour & $47.1 \pm 5.1$ & $22.9 \pm 5.5$ & 0.001 \\
$24^{\text {th }}$ hour & $47.0 \pm 9.5$ & $22.9 \pm 5.7$ & 0.001 \\
$28^{\text {th }}$ hour & $44.2 \pm 5.7$ & $22.3 \pm 6.2$ & 0.001 \\
$32^{\text {nd }}$ hour & $41.7 \pm 4.9$ & $22.5 \pm 5.3$ & 0.001 \\
$36^{\text {th }}$ hour & $43.0 \pm 4.7$ & $22.3 \pm 4.4$ & 0.001 \\
$40^{\text {th }}$ hour & $43.5 \pm 5.4$ & $22.5 \pm 6.4$ & 0.001 \\
$44^{\text {th }}$ hour & $41.7 \pm 6.5$ & $21.7 \pm 4.3$ & 0.001 \\
$48^{\text {th }}$ hour & $40.6 \pm 4.8$ & $21.7 \pm 5.3$ & 0.001 \\
\hline
\end{tabular}

Table-IV

Post-operative pain score (VAS) after extubation at during coughing in different time interval of the study patients $(n=60)$

\begin{tabular}{lccc}
\hline $\begin{array}{l}\text { Four hours time } \\
\text { interval }\end{array}$ & $\begin{array}{c}\text { Group Ax } \\
(\mathrm{n}=30) \\
\text { Mean } \pm S D\end{array}$ & $\begin{array}{c}\text { Group B } \\
(\mathrm{n}=30) \\
\text { Mean } \pm S D\end{array}$ & pvalue \\
\hline $8^{\text {th }}$ hour & $53.7 \pm 7.5$ & $28.3 \pm 8.3$ & 0.001 \\
$12^{\text {th }}$ hour & $56.7 \pm 8.2$ & $28.7 \pm 9.5$ & 0.001 \\
$16^{\text {th }}$ hour & $50.8 \pm 6.1$ & $25.8 \pm 7.5$ & 0.001 \\
$20^{\text {th }}$ hour & $50.2 \pm 7.2$ & $24.6 \pm 6.6$ & 0.001 \\
$24^{\text {th }}$ hour & $48.5 \pm 9.3$ & $23.7 \pm 6.6$ & 0.001 \\
$28^{\text {th }}$ hour & $45.7 \pm 5.4$ & $22.9 \pm 6.4$ & 0.001 \\
$32^{\text {nd }}$ hour & $45.0 \pm 4.3$ & $23.1 \pm 5.5$ & 0.001 \\
$36^{\text {th }}$ hour & $45.2 \pm 6.8$ & $22.9 \pm 4.6$ & 0.001 \\
$40^{\text {th }}$ hour & $45.0 \pm 5.4$ & $23.1 \pm 7.6$ & 0.001 \\
$44^{\text {th }}$ hour & $43.2 \pm 6.5$ & $21.7 \pm 4.3$ & 0.001 \\
$48^{\text {th }}$ hour & $42.8 \pm 3.5$ & $22.4 \pm 5.6$ & 0.001 \\
\hline
\end{tabular}

The following table showed mean distribution of postoperative sedation score at first six hour (hourly) and found significant $(p<0.05)$ change between two groups except 1 st hour, which was not significant $(p>0.05)$ (Table $\mathrm{V})$.

Table-V

Mean distribution of post-operative sedation score at first six hour (hourly) of the study patients $(n=60)$

\begin{tabular}{lccc}
\hline One hour interval & $\begin{array}{c}\text { GroupA } \\
(\mathrm{n}=30) \\
\text { Mean } \pm \text { SD }\end{array}$ & $\begin{array}{c}\text { Group B } \\
(\mathrm{n}=30) \\
\text { Mean } \pm S D\end{array}$ & pvalue \\
\hline $1^{\text {st }}$ hour & $2.9 \pm 0.3$ & $2.8 \pm 0.5$ & 0.352 NS \\
$2^{\text {nd }}$ hour & $2.8 \pm 0.5$ & $2.1 \pm 0.6$ & 0.001 \\
$3^{\text {rd }}$ hour & $2.4 \pm 0.7$ & $1.4 \pm 0.5$ & 0.001 \\
$4^{\text {th }}$ hour & $2.1 \pm 0.5$ & $1.1 \pm 0.3$ & 0.001 \\
$5^{\text {th }}$ hour & $1.4 \pm 0.5$ & $1.0 \pm 0.0$ & - \\
$6^{\text {th }}$ hour & $1.15 \pm 0.4$ & $1.0 \pm 0.0$ & - \\
\hline
\end{tabular}

The following table showed Status of rescue analgesics received and found $16(53.3 \%)$ and $6(20.0 \%)$ needed analgesia in group $A$ and group $B$ respectively and the difference was statistically significant $(p<0.05)$ in chi square test (Table $\mathrm{VI}$ ). 
Table-VI

Status of rescue analgesics received by the study patients $(n=60)$

\begin{tabular}{lcccccc}
\hline Rescue analgesics & \multicolumn{2}{c}{$\begin{array}{c}\text { Group A } \\
(n=30)\end{array}$} & & \multicolumn{2}{c}{$\begin{array}{c}\text { Group B } \\
(n=30)\end{array}$} & p value \\
\cline { 2 - 3 } & $\mathrm{N}$ & $\%$ & & $\mathrm{n}$ & $\%$ & \\
\hline Received & 16 & 53.3 & & 6 & 20.0 & 0.015 \\
Not received & 14 & 46.7 & & 24 & 80.0 & \\
\hline
\end{tabular}

The following table showed the requirement of postoperative mechanical ventilation i.e. The mean extubation hours were $7.4 \pm 1.09$ hours in group $A$ and $5.3 \pm 0.81$ hours in group $B$. The mean ICU stay was $72.9 \pm 9.2$ hours in group $A$ and $57.1 \pm 12.0$ hours in group $B$ and the difference was statistically significant $(p<0.05)$ in unpaired t-test (Table VII).

\section{Table-VII}

Mean distribution of extubation hour and duration of ICU stay of the study patients $(n=60)$

\begin{tabular}{lccc}
\hline & $\begin{array}{c}\text { Group A } \\
(n=30) \\
\text { Mean } \pm S D\end{array}$ & $\begin{array}{c}\text { Group B } \\
(n=30) \\
\text { Mean } \pm S D\end{array}$ & p value \\
\hline Extubation hours & $7.4 \pm 1.09$ & $5.3 \pm 0.81$ & 0.001 \\
ICU stay & $72.9 \pm 9.2$ & $57.1 \pm 12.0$ & 0.001 \\
\hline
\end{tabular}

No post-operative complication was observed in both groups.

\section{Discussion:}

This prospective, randomized observational comparative study was carried out with an aim to compare, which one more efficient for short duration of postoperative ventilation with the length of stay in intensive care unit and optimal pain relief after off pump coronary artery bypass surgery (OPCAB) between combined High Thoracic Epidural anaesthesia (HTEA) with General anaesthesia (GA) and general anaesthesia (GA) alone.

A total of 60 patients undergo elective CABG on off pump having ASA grade I, II, III and IV and NYHA class I, II, III and IV were included in the study at the National Institute of Cardiovascular Diseases and Hospital, Sher-E-Bangla Nagar, Dhaka and they were randomly allocated by lottery methods in two groups; group A: using GA alone and group B: using HTEA+ GA.

Regarding the mean pain score during maintenance with ventilator with awareness in this study at first fourth hour was significantly $(p<0.05)$ higher in group $A$, which was $53.4 \pm 9.4$ and $26.0 \pm 8.7$ in group $A$ and group $B$ respectively.
Kessler et al. (2005) have assessed the VAS (0-100mm) at rest were subsequently higher in group $A$ than group $B$ at all times after surgery, always reaching significance level except at 48 hours. Similarly Salvi et al. (2004) assessed the VAS $(0-10 \mathrm{~mm})$ for the first 24 hour period were 0.9 at rest and 1.7 during coughing in each patients the VAS score always less than $<2$, which indicating that the post-operative pain relief was excellent in their study patients (group B). In the present study it was found that post-operative pain score VAS $(0-100 \mathrm{~mm})$ was $>40$ in group $A$ and $<30$ in group $B$ after extubation at rest, movement and during coughing which were significantly $(p<0.05)$ higher in group $A$ in all the different follow-up times. The results obtained in the present study are comparable with the above studies.

In the current series it was observed that the status of rescues analgesics need $53.3 \%$ in group A and $20.0 \%$ group $B$ and the difference was statistically significant $(p<0.05)$.

In the present study post-operative sedation score at first hour was almost similar between two group, however the remaining times sedation score were significantly $(p<0.05)$ higher in group A. Kessler et al. (2005) reported that sedation score were significantly higher at 6 hour post-operatively in group A.

Most of the patients in group B awareness were occurred at 2 hour after arrival at Intensive care unit but 4 hour later in group A. After 4 to 5 hour later after arrival at Intensive care unit it was observed that group B patients awake from sedation as like a normal healthy person with sound sleep, but in patients group A most of them looked anxious.

It was observed in the current study that post-operative level of consciousness score at different times almost similar between two groups. No significant $(p>0.05)$ change was found between two groups.

A conscious and oriented patient will communicate their needs and cooperate with the medical staff providing post-operative care. The ability to concentric and learn instructions may facilitate tactual extubation, chest tube removal and cooperation with physiotherapist and moving staff.

In this study it was observed that the level of satisfaction with the anaesthetic technique was $36.7 \%$ and $83.3 \%$ mentioned good in group A and group B respectively, which was statistically significant $(p<0.05)$. Kessler et al. (2005) found identical level of satisfaction with the anaesthetic technique.

Patients satisfaction is as much related to the comparison between anticipated and experienced pain 
as it is to the actual level of pain experience. Satisfaction is achieved when a situation is better than expected and dissatisfaction when one is worse than expected. Patients undergoing cardiac surgery are very concerted regarding post-operative pain and tend to preoperatively expect more intense post-operative pain than that actually experienced. So in the present study patients who were received HTEA (group B) express very high satisfaction level than the groups A only. In the present study the patients in both groups were asked during $3^{\text {rd }}$ postoperative day about their anesthetic technique and their feeling in comparison with the other patients who underwent OPCAB in the same day or next day at the same cardiac post anaesthesia care unit, a specialized unit caring a exclusively for open heart surgery patients. The patient group B, most of the patient expressed their feeling good and few of them expressed fair and none of them not fair. But in group A, 23.0\% patients expressed their feeling not fair.

In this study no post-operative complication was found between two groups. In a study Scott (2001) done a study on 202 patients in group A and 206 in group B and found the incidence of postoperative confusion was $5.5 \%$ and $1.5 \%$ in group $A$ and group $B$ respectively. The incidence of CVA was $3.0 \%$ in group $A$ and $1.0 \%$ in group B. Similar technique was used by Tuman et al. (1991) on outcome of major vascular surgery and found that prolong mechanical ventilation $12.5 \%$ in group $A$ and $2.5 \%$ in group $B$, reintubation $2.5 \%$ in group $A$ and none was found in group $B$, neurologic complications $7.5 \%$ in group $A$ and none was found in group $B$.

In this study it was found that the mean ventilation hours was significantly $(p<0.05)$ higher in group $A$, which were $7.4 \pm 1.09$ in group $A$ and $5.3 \pm 0.81$ hours in group $B$. Similarly, the mean ICU stay was also significantly $(p<0.05)$ higher in group $A$, which were $72.9 \pm 9.2$ hours in group A and $57.1 \pm 12.0$ hours in group B. Kessler et al. (2005) observed the higher mean ventilation hours in group A, which was $5.0 \pm 2.6$ hour in group $A$ and $3.7 \pm 2.4$ hours in group $B$. The mean ICU stay was also higher in group A, which was $11.2 \pm 7.9$ hours and $9.2 \pm 8.1$ hours in group B. Salvi et al. (2004) observed the mean ventilation hour was $4.6 \pm 2.9$ in group B and the mean ICU stay was $36.0 \pm 19.2$ hours.

\section{Conclusion:}

Based on the present study shows that anaesthetic technique High Thoracic Epidural Anaethesia with General Anaesthesia (HTEA with GA) during off pump coronary artery bypass surgery (OPCAB) shortens the post-operative requirement of mechanical ventilation with the duration of ICU stay and optimize the pain relief with satisfaction than GA only.

\section{References:}

1. Casalino S, Mangia F, Stelian E, Novelli E, Diena M and Tesler UF. High Thoracic Epidural Anesthesia in cardiac surgery. Tex Heart Inst J 2006; 33(2):148153.

2. Chakravarthy $\mathrm{M}$, Thimmangowda $\mathrm{P}$, Krishnamurthy J, Nadiminti S, Jawali V. Thoracic epidural anesthesia in cardiac surgical patients: a prospective audit of 2,113 cases. J Cardiothorac Vase Anesth 2005;19:44-48.

3. Chancy MA. Intrathecal and Epidural Anesthesia and Analgesia for Cardiac Surgery. Anesth Analg 2006; 102:45-64.

4. Dal D, Kanbak M, Caglar M, AyparU. A background infusion of morphine does not enhance postoperative analgesia after cardiac surgery.

5. Can J Anesth 2003; 50(5): 476-479.

6. Dean GD and Kim SJ. A survey of spinal and epidural techniques in adult cardiac surgery. $J$ Cardiothoracic Vase Anesth 2001;15:158-168.

7. Ganapathy S, Murkin JM, Dobkowski W, Boyd D. Stress and inflammatory response after beating heart surgery versus conventional bypass surgery: the role of thoracic epidural anesthesia. Heart Surg Forum 2001;4:323-7.

8. Hasenbos M, Liem TH, Kerkkamp H. The influence of high thoracic epidural analgesia on the cardiovascular system. Acta Anaesthesiol Belg 1988;39:49-54.

9. Hemmarling TM, Prieto I, Choiniere JL, Basile F, Fortier JD. Ultra-fast-track anesthesia in off-pump coronary artery bypass grafting: a prospective audit comparing opioid based anesthesia vs. thoracic epidural -based anesthesia. an J Anaesth 2004;51:163-8.

10. Ho AM, Chung DC, Joynt GM. Neuroaxial blockade and hematoma in cardiac surgery: estimating the risk of a rare event that has not (yet) occurred.

11. Chest 2000;117:551-555.

12. Joachimsson PO, Nystrom SO, Tyden H. Early extubation after coronary artery surgery in efficiently rewarmed patients: a postoperative comparison of opioid anesthesia versus inhalation anesthesia and thoracic epidural analgesia. 
13. J Cardiothorat Anesth 1989;3:444-54.

14. Johannsen UJ, Mark AL, Marcus ML. Responsiveness to cardiac sympathetic nerve stimulation during maximal coronary dilation produced by adenosine. Circ Res 1982;50:510-7.

15. Katsuda Y, Egashira K, Ueno H. ATPsensitive K+ channel opener pinacidil augments beta adrenoceptor induced coronary vasodilatation in dogs. Am J Physiol 1996;270:H2210-5.

16. Kehlet $\mathrm{H}$. Surgical stress: the role of pain and analgesia. Br J Anaesth 1989;63:189-95.

17. Kessler P, Aybek T, Neidhart G, dogan S, Lischke V, Bremerich DH. Comparison of three anesthetic techniques for Off-pump coronary artery bypass grafting: general anaesthesia, Combined general and high thoracic epidural anaesthesia, or high thoracic epidural anesthesia alone.

18. Kleinman W. Regional anesthesia and pain management. In: Morgan GE, Mikahali MS, Murray MJ (eds), Clinical anesthesiology, $3^{\text {rd }}$ edn. The McGraw-Hill companies, United state of America 2002; pp. 253-280.

19. Kock M, Blomberg S, Emanuelsson H. Thoracic epidural anesthesia improves global and regional left ventricular function during stress induced myocardial ischemia in patients with coronary artery disease. Anesth Analg 1990;71:625-30.

20. Kock M, Blomberg S, Emanuelsson H. Thoracic epidural anesthesia improves global and regional left ventricular function during stress induced myocardial ischemia in patients with coronary artery disease. Anesth Analg 1990;71:625-37.

21. Leim TH, Hasenbos MA, Booij LH, Geilen MJ. Coronary artery bypass grafting using two different anesthetic techniques. Part 2: Postoperative outcome. J Cardiothorac Vase Anesth 1992;6: 156-61.

22. Liu SS, Block BM, Wu CL. Effect of perioperative central neuroaxial analgesia on outcome after coronary artery bypass surgery: a meta analysis. Anaes/hesiology 2004;101:153-161.

23. Loick HM, Schmidt C, Van Aken H. High thoracic epidural anesthesia, but not clonidine, attenuates the perioperative stress response via sympatholysis and reduces the release of troponin $\mathrm{T}$ in patients undergoing coronary artery bypass grafting. Anesth Analg 1999;88:701-9.
24. Meifsner A, Rolf $\mathrm{N}$ and Aken HV. Thoracic epidural anesthesia and the patients with heart disease: benefits, risks and controversies. Anesth Analg 1977;85:517-528.

25. Meissner A, Eckardt L, Kirchhof P. Effects of thoracic epidural anesthesia with and without autonomic nervous system blockade on cardiac monophasic action potentials and effective refractoriness in awake dogs.

26. Anesthesiology 2001; 95: 132-8; discussion 6A.

27. Meissner A, Rolf N, Van Aken H. Thoracic epidural anesthesia and the patient with heart disease: benefits, risks, and controversies. Anesth Analg 1997; 85: 517-28.

28. Mergner GW, Stolte AL, Frame WB. Combined epidural analgesia and general anesthesia induce ischemia distal to a severe coronary artery stenosis in swine. Anesth Analg 1994;78:37-45.

29. Miller VM, Vanhoutte PM. Muscular and endothelial responsiveness to alpha adrenergic activation in canine blood vessels. Physiologist 1984;27:282-6.

30. Millers Anaesthesia $6^{\text {th }}$ ed Ronald d Millar 2005; $p$ 318-326, 108-109,144-147.

31. Mohrman DE, Feigl EO. Competition between sympathetic vasoconstriction and metabolic vasodilatation in the canine coronary circulation. Circ Res 1978;42:79-86.

32. Moore CM, Cross MH, desborough JP, Burrin JM, MacdonaldIA, Hall GM. Hormonal effects of thoracic extradural analgesia for cardiac surgery. $\mathrm{Br} \mathrm{J}$ Anaesth 1995;75:387-93.

33. Mudge GH Jr, Goldberg S, Gunther S. Comparison of metabolic and vasoconstrictor stimuli on coronary vascular resistance in man. Circulation 1979;59:544-50.

34. Nabel EG, Ganz I, Gordon JB. Dilation of normal and constriction of atherosclerotic coronary arteries caused by the cold pressor test. Circulation 1988;77:43-52.

35. Nakhostine N, Lamontagne D. Contribution of prostaglandins in hypoxiadinduced vasodilatation in isolated rabbit hearts: relation to adenosine and KATP channels.

36. Pfluzers Arch 1994:428: 526-32.

37. Olivier JF and Le N. Comparison of the three different epidural solutions in off-pump cardiac surgery: pilot study. Br J Anaesth 2005;95(5):685-691. 
38. Reiz S, Nath S, Ponten E. Hemodynamic effects of prenalterol, a beta adrenoreceptor agonist, in hypotension induced by high thoracic epidural block in man. Acta Anaesthesiol Stand 1979;23:93-6.

39. RoccoMB, Nabel EG, Serwyn AP. Circadian rhythms and coronary artery disease. Am J Cardiol 1987; 59: $13 \mathrm{C}-7 \mathrm{C}$.

40. Roizen MF. Should we all have a sympathectomy at birth or at least preoperatively. Anaesthesiology 1988;68:482-4.

41. Rolf N, Van de Velde M, Wouters PF. Thoracic epidural anesthesia improves functional recovery from myocardial stunning in conscious dogs. Anesth Analg 1996;83:935-40.

42. Ronald A, AbdulAziz KA. Thomas George day and MartinScott, In patient undergoing cardiac surgery , thoracic epidural analgesia combined with general anaesthesia results in faster recovery and fewer complications but does not affect length of hospital stay. Interact Cardio Vase Surg 2006;5:207-216.

43. Royse C, Royse A, Soeding P, Blake D, Pang J. Prospective randomised trial of high thoracic epidural analgesia for coronary artery bypass surgery. AnnThorac Surg 2003; 75:93-100.

44. Rubanyi GM, Vanhoutte PM. Endothelium removal decreases relaxation of coronary arteries caused by beta adrenergic agonists and adenosine. $J$ Cardiovasc Iharmacol 1985;7:139-44.

45. Sato K, Yamamura T, Murakami F. Thoracic epidural anaesthesia combined with enflurane anaesthesia reduces atrioventricular conduction in dogs. Can $J$ Anaesth 1990;37: 813-8.

46. Salvi L, Sisillo E, Brambillasca C, Juliano G, Salis $S$ and Marino MR. High thoracic epidural anesthesia for off-pump coronary artery bypass surgery. $J$ Cardiothorac Vasc Anesth 2004;18(3):256-62.

47. Scott MB, Turfrey DJ, Ray DA. Aprospective randomized study of the potential benefits of thoracic epidural anaesthesia and analgesia in patients undergoing coronary artery bypass grafting. Anesth Analg 2001;93(5):28-35.

48. Sjogren S, Wright B. Circulatory changes during continuous epidural blockade. Acta Anaesthesiol Stand Suppl 1972;46: 5-25.

49. Stenseth R, Berg EM, Bjella L, Christensen O, Levang OW, Gisvold SE. Effects of thoracic epidural analgesia on coronary hemodynamic and myocardial metabolism in coronary artery bypass surgery. $J$ Cardiothorac Vasc Anesth 1995; 9: 503-9.

50. Stenseth R, Bjella L, Berg EM, Christensen O, Levang OW, Gisvold SE. Thoracic epidural analgesia in aortocoronary bypass surgery. I: haemodynamic effects. Acta Anaesthesiol Scand 1994; 38: 826-33.

51. Stenseth R, Bjella L, Berg EM, Christensen O, Levang OW, Gisvold SE. Thoracic epidural analgesia in aortocoronary bypass surgery. II: effects on the endocrine metabolic response. Acta Anaesthesiol Scand 1994; 38: 834-9.

52. Tuman KJ, McCarthy RJ, March RJ, DeLaria GA, Patel RV, Ivankovich AD. Effects of epidural anesthesia and analgesia on coagulation and outcome after major vascular surgery. Anesth Analg 1991; 73: 696-704.

53. Turfrey DJ, Ray DA, Suteliffe NP, Ramayya P, Kenny GN, Scott NB. Thoracic epidural anaesthesia for Coronary artery bypass graft surgery. Effects on postoperative complications. Anaesthesia 1997;52:1090-5.

54. Visser WA, Liem TH, Egmond JV and Gielen MJ. Extension of sensory blockade after thoracic epidural administration of a test dose of lidocaine at three different levels. Anesth Analg 1998;86:332335.

55. Wolman RL. Patient controlled analgesia following thoracic surgery. In: Gravlee a Rauk (Eds). Pain management in cardiothoracic surgery. Philadelphia: Lippincort company 1993: pp. 59-87. 